\title{
Separation of Legionella pneumophila Proteases and Purification of a Protease Which Produces Lesions Like Those of Legionnaires' Disease in Guinea Pig Lung
}

\author{
By J. W. CONLAN,* A. BASKERVILlE AND L. A. E. ASHWORTH \\ Experimental Pathology Laboratory, PHLS Centre for Applied Microbiology and Research, \\ Porton Down, Salisbury SP4 OJG, UK
}

(Received 29 October 1985)

\begin{abstract}
Six discrete protease activities were recovered from the supernatant broth of Legionella pneumophila cultures by ion-exchange chromatography. One of these demonstrated in vitro activity against collagen, casein and gelatin. When administered into the lungs of guinea-pigs this protease elicited lesions which were pathologically similar to those seen in clinical and experimentally induced Legionnaires' disease.
\end{abstract}

\section{INTRODUCTION}

In human Legionnaires' disease (Blackmon et al., 1981) and during experimental pulmonary infection of guinea pigs (Baskerville et al., 1981, 1983), Legionella pneumophila gives rise to an acute fibrinopurulent pneumonia. The bacterial components and host tissue factors which contribute to the pulmonary damage are not understood. In experimental pneumonias caused by Serratia marcescens (Lyerly \& Kreger, 1983) and Pseudomonas aeruginosa (Gray \& Kreger, 1979; Woods et al., 1982), proteases have been shown to be key components in the pathogenesis of pulmonary lesions. Immunization with proteases confers protection against lethal pneumonia in mink (Homma et al., 1978) and mice (Lyerly \& Kreger, 1983) infected with $P$. aeruginosa or $S$. marcescens, respectively. The difference in gelatinase profiles demonstrated for virulent and avirulent strains of Bacteroides nodosus (Kortt et al., 1983) indicates also that some protease activities may be virulence determinants.

There has been speculation about the possible involvement of proteases in the pathogenesis of Legionnaires' disease but no studies of in vivo effects of Legionella proteases have been reported. Many extracellular proteolytic enzyme activities have been described for Legionella pneumophila, including chymotrypsin-like (Berdal et al., 1982), caseinase (Thompson et al., 1981 ; Berdal \& Fossum, 1982), gelatinase (Thompson et al., 1981), serum protein degrading protease (Müller, 1980) and multiple aminopeptidase (Müller, 1981) activities. To date these activities have been demonstrated either in supernatants of broth cultures or by growing $L$. pneumophila on solid media containing specific substrates. Consequently it is not known whether the observed activities are due to one or a few enzymes, each with broad specificity, or to several highly specific enzymes.

This paper describes the isolation from L. pneumophila of six discrete proteases, one of which causes pulmonary damage consistent with the pathological findings in legionellosis. The detailed pathology of the protease-induced damage is the subject of a separate report (Baskerville et al., 1986).

\footnotetext{
Abbreviations: AP, aminopeptidase; $N$-CBZ-, $N$-carbobenzoxy-; $-O$-NP, $p$-nitrophenyl ester; -pNA, $p$-nitroanilide; PMN, polymorphonuclear leucocyte(s); TEMED, $N, N, N^{\prime}, N^{\prime}$-tetramethylethylenediamine.
} 


\section{METHODS}

Chemicals and reagents. Tris, ammonium persulphate, TEMED, L-Ala-pNA, Gly-pNA, L-Arg-pNA, L-LeupNA, L-Lys-pNA, L-Pro-pNA, $N$-CBZ-L-Phe- $O$-NP, $N$-CBZ-L-Tyr-O-NP, dye-impregnated collagen (Azocoll) and elastin-congo red were from Sigma. Succinyl-O-Me-Arg-Pro-Tyr-pNA (S2586) and succinyl-Ala-Pro-TyrpNA (S2561) were from KabiVitrum. Acrylamide and bisacrylamide (both Electran grade), Coomassie brilliant blue, glycine (chromatographically pure) and $M_{\mathrm{r}}$ markers were from BDH. Gelatin and sodium caseinate (Nutrose) were from Difco. Sephadex G-50 and G-100 were from Pharmacia, and DEAE-cellulose was from Whatman. Other chemicals were analytical reagent grade. L. pneumophila lipopolysaccharide was prepared from the phenol phase of a phenol/water extract of organisms as reported by Conlan \& Ashworth (1986).

Organisms. Serogroup 1 L. pneumophila strains were Corby (a human isolate kindly provided by Dr R. A. Swann, John Radcliffe Hospital, Oxford, UK) and Corby avirulent, obtained in this laboratory (Dr R. B. Fitzgeorge) by multiple passage on charcoal/yeast extract (CYE) agar (Edelstein, 1981). Strain Corby is virulent for guinea pigs by aerosol administration (Jepras et al., 1985) whereas Corby avirulent fails to cause respiratory disease (R. B. Fitzgeorge, personal communication).

Culture conditions. Stock cultures, stored at $-70^{\circ} \mathrm{C}$, were thawed and used to inoculate starter cultures in $100 \mathrm{ml}$ yeast extract broth (YEB; Ristroph et al., 1980) in $500 \mathrm{ml}$ flasks, incubated aerobically at $37^{\circ} \mathrm{C}$ for $24 \mathrm{~h}$ on an orbital shaker. Purity was then checked by Gram's stain and by the ability of the organism to grow on CYE agar but not on blood agar. Cultures for enzyme production ( $500 \mathrm{ml}$ YEB in 2-litre flasks) were inoculated with $5 \mathrm{ml}$ starter culture and incubated as above for $16 \mathrm{~h}$. Organisms were removed by centrifugation at $1500 \mathrm{~g}$ for $1 \mathrm{~h}$ and the supernatant YEB was sterilized by membrane filtration (Pall $0.22 \mu \mathrm{m}$ filters).

Enzyme separation. All steps were performed at $4^{\circ} \mathrm{C}$. Sterile supernatant broth was concentrated 100 -fold over a YM10 filter (Amicon; $M_{\mathrm{r}}$ cut-off $>10000$ ) in a stirred cell. The concentrate was dialysed against $0.05 \mathrm{M}-\mathrm{Tris} / \mathrm{HCl}$ $\mathrm{pH} 8.5$ (buffer A) containing $0.1 \mathrm{M}-\mathrm{NaCl}$ and $12 \mathrm{ml}$ applied to a column $(2.2 \times 40 \mathrm{~cm})$ of DEAE-cellulose (pretreated according to the manufacturers' instructions) equilibrated with $0 \cdot 1 \mathrm{M}-\mathrm{NaCl}$ in buffer $\mathrm{A}$. Using a flow rate of $15 \mathrm{ml} \mathrm{h}^{-1}$ and collecting $10 \mathrm{ml}$ fractions, the column was eluted with $120 \mathrm{ml}$ starting buffer and then with a linear gradient of $\mathrm{NaCl}(0.1-0.5 \mathrm{M}$ in buffer $\mathrm{A}$; gradient volume $600 \mathrm{ml})$. The column was washed finally with $300 \mathrm{ml} 1.0 \mathrm{M}-\mathrm{NaCl}$ in buffer $\mathrm{A}$. Individual fractions were assayed for enzyme activities as described below. Fractions containing discrete enzyme activities were pooled separately, concentrated to their starting volumes $(12.0 \mathrm{ml})$ and assayed in the guinea pig skin test (see below).

Purification of tissue-destructive protease. Supernatant broth from $16 \mathrm{~h}$ cultures was concentrated 200 -fold (YM10) and $20 \mathrm{ml}$ of the concentrate dialysed against $0.05 \mathrm{M}-\mathrm{Tris} / \mathrm{HCl} \mathrm{pH} 7.5$ containing $0.005 \% \mathrm{NaN}_{3}$ (buffer $\mathrm{B}$ ) and applied to a Sephadex G-100 column $(3 \cdot 2 \times 90 \mathrm{~cm})$. The column was eluted with buffer B at a flow rate of $15 \mathrm{ml} \mathrm{h}^{-1}$, and $10 \mathrm{ml}$ fractions were assayed individually for enzyme activities as described below. Fractions causing casein precipitation were pooled, concentrated (YM5, Amicon), dialysed against buffer A containing $0 \cdot 1 \mathrm{M}-\mathrm{NaCl}$ and applied to a DEAE-cellulose column $(2 \cdot 2 \times 40 \mathrm{~cm})$. The column was washed with 1 vol. starting buffer then with a $0 \cdot 1-1.0 \mathrm{M}-\mathrm{NaCl}$ gradient of equivalent slope to the $0.1-0.5 \mathrm{M}$ gradient used above. Caseinprecipitating fractions were re-concentrated, dialysed against buffer B and applied to a Sephadex G-50 column $(2.2 \times 90 \mathrm{~cm})$. This was eluted at a flow rate of $5 \mathrm{ml} \mathrm{h}^{-1}$ and $5 \mathrm{ml}$ fractions were collected.

$S D S-P A G E$. Lyophilized samples containing 20-80 $\mu$ g protein were analysed using the Laemmli (1970) buffer system with a $12 \%$ separating gel. Running conditions were $25 \mathrm{~mA}$ until the bromophenol blue tracking dye had migrated to within $1 \mathrm{~cm}$ of the bottom of the gel. After electrophoresis, gels were stained in a $0.05 \%$ solution of Coomassie brilliant blue in acetic acid/2-propanol $/ \mathrm{H}_{2} \mathrm{O}\left(1: 2: 7\right.$, by vol.) overnight at $37^{\circ} \mathrm{C}$, and destained in several changes of acetic acid/2-propanol/ $\mathrm{H}_{2} \mathrm{O}(1: 1: 8$, by vol.).

Enzyme assays. (a) Using synthetic substrates. Chromogenic p-nitroanilide substrates were dissolved in distilled water to $1.0 \mathrm{mM}$. CBZ-nitrophenyl substrates were dissolved in DMSO and diluted to $0.1 \mathrm{mM}$ in water immediately before use. Assays were done in 96-well microtitre plates with $50 \mu \mathrm{l}$ test material, $100 \mu \mathrm{l} 0.05 \mathrm{M}$-sodium phosphate buffer $\mathrm{pH} 7.0$ and $100 \mu \mathrm{l}$ substrate in each well. The plates were covered, incubated at $37^{\circ} \mathrm{C}$ for $1 \mathrm{~h}$ and colour read at $405 \mathrm{~nm}$ on a microplate reader (Titertek Multiscan).

For more accurate quantification of enzyme activities, $50 \mu \mathrm{l}$ test solution was added to a mixture (at $37^{\circ} \mathrm{C}$ ) of $0.5 \mathrm{ml}$ substrate and $2 \mathrm{ml}$ phosphate buffer $\mathrm{pH} 7.0$ in a $1 \mathrm{~cm}$ cuvette. Using heat-inactivated test solution $\left(100^{\circ} \mathrm{C}\right.$, $10 \mathrm{~min}$ ) as a blank, the absorbance at $405 \mathrm{~nm}$ was measured in a spectrophotometer (Pye-Unicam SP500) with a sample compartment at $37^{\circ} \mathrm{C}$. Enzyme activities were expressed as $\mu$ mol product released $\min ^{-1}$ at $37^{\circ} \mathrm{C}$ and specific activities calculated on the basis of protein content of the sample measured by the method of Bradford (1976).

(b) Using protein substrates. Collagenase and elastase activities were assayed by incubation at $37^{\circ} \mathrm{C}$ of $100 \mu \mathrm{l}$ test solution with $20 \mathrm{mg}$ of the appropriate dye-impregnated substrate in $5 \mathrm{ml} 0.05 \mathrm{M}$-phosphate buffer pH 7 . Gelatinase activity was detected using gelatin incorporated into agar $[0.25 \%(\mathrm{w} / \mathrm{v})$ gelatin (Difco), $1.0 \%(\mathrm{w} / \mathrm{v})$ agar, $0.001 \%(\mathrm{w} / \mathrm{v}) \mathrm{NaN}_{3}$ in $0.2 \mathrm{M}-\mathrm{Tris} / \mathrm{HCl} \mathrm{pH} \mathrm{7.2]}$. Molten gelatin-agar $(20 \mathrm{ml})$ was poured into $12 \mathrm{~cm} \mathrm{Petri}$ dishes, test materials ( $50 \mu \mathrm{l}$ volumes) were placed in wells $(4 \mathrm{~mm}$ diameter $)$ cut in the solidified medium and the 
dishes were incubated for $16 \mathrm{~h}$ at $37^{\circ} \mathrm{C}$. The gels were then treated with a solution of $15 \%(\mathrm{w} / \mathrm{v}) \mathrm{HgCl}$ in $2 \mathrm{M}-\mathrm{HCl}$, causing the gelatin-agar to become milky white except for clear zones where proteolysis had occurred. Caseinprecipitating activity was measured by a similar method using a medium containing $1.0 \%$ sodium caseinate (Difco), $1.0 \%$ agar and $0.001 \% \mathrm{NaN}_{3}$ in $50 \mathrm{~mm}$-phosphate buffer $\mathrm{pH} 6.2$. After incubation, caseinase activity was evident as a zone of precipitate around positive wells without any treatment of the medium. Caseinase activity could not be quantified by measuring the zones of precipitation. A limiting dilution technique was therefore used; 1 unit of activity was defined as the amount of enzyme required to yield the smallest detectable zone of precipitate.

Animal studies. Female Dunkin Harley guinea pigs of category 4 health status (Medical Research Council, 1974) and weighing $350-450 \mathrm{~g}$ were used.

(a) Intradermal inoculation. A doubling dilution series of test material was made in PBS $(8 \mathrm{~g} \mathrm{NaCl}, 0 \cdot 2 \mathrm{~g} \mathrm{KCl}$, $1.15 \mathrm{~g} \mathrm{Na}_{2} \mathrm{HPO}_{4}$ and $0.2 \mathrm{~g} \mathrm{KH}_{2} \mathrm{PO}_{4}$ per litre, $\mathrm{pH} \mathrm{7.2)} \mathrm{and} 100 \mu \mathrm{l}$ of each dilution injected into a site on the shaved flank (eight sites per animal). Reactions were examined after $2 \mathrm{~h}$ and scored in comparison to controls (detailed in Results).

(b) Intratracheal and intranasal inoculation. Guinea pigs were anaesthetized with ether, and $0.5-0.8 \mathrm{ml}$ concentrated culture supernatant or protease solution was instilled into the nostrils. Control animals were given concentrated culture medium or heat-inactivated protease, respectively. Another group was anaesthetized by intraperitoneal injection of a mixture of Midazolam ('Hypnovel', Roche Products) and fentanyl citrate-fluanisone ('Hypnorm', Crown Chemical Co.) and the trachea was surgically exposed via a ventral mid-line incision in the neck. Protease solution or control medium was inoculated intratracheally and the skin incision closed with metal clips.

Pathology. Animals were killed with ether $0.5 \mathrm{~h}, 3 \mathrm{~h}, 24 \mathrm{~h}$, and 2,3 and $4 \mathrm{~d}$ after inoculation and the trachea and lungs were removed en bloc. For light microscopy the trachea, lungs, brain, liver, kidney and heart were fixed in $10 \%(\mathrm{v} / \mathrm{v})$ buffered neutral formalin, processed by standard procedures and embedded in paraffin wax. For histological investigation of the skin reactions, animals were killed at $3 \mathrm{~h}$ and $24 \mathrm{~h}$ and the areas of skin bearing lesions were excised. Blocks of tissue were taken to include the entire lesion, fixed in formalin, and processed as above. Sections from all tissues were cut at $5 \mu \mathrm{m}$ and stained with haematoxylin and eosin. Selected sections were stained by the methods of Verhoeff-van Gieson (Culling, 1963) and Gordon and Sweet (Culling, 1963).

\section{RESULTS}

\section{L. pneumophila proteases}

Culture supernatants of both Corby and Corby avirulent strains of $L$. pneumophila contained alanine aminopeptidase (Ala-AP), Lys-AP, Phe-AP, two Leu-APs and a chymotrypsin-like activity as demonstrated by cleavage of the chromogenic tripeptides S2561 and S2586. Collagenase, gelatinase and casein-precipitating (caseinase) activities were also found. No elastase, tyrosine-AP or proline-AP activities were detected.

\section{Ion-exchange separation of proteases}

DEAE-cellulose chromatography of culture supernatant resulted in separation of all the above activities against chromogenic substrates into distinct peaks (Fig. 1). A number of gelatinases (Fig. $2 a$ ), producing zones of hydrolysis of different size, were also resolved. These coincided with activities against the chromogenic substrates except for Lys-AP where gelatinase activity was associated with the front and tail, but not with the peak, of enzyme activity. The strongest gelatinase activity was associated with fractions which cleaved S2586, extending into adjacent fractions which lacked detectable activity against S2586. This may simply reflect a difference in sensitivity of the two assays (see also caseinase profile, Fig. $2 b$ ).

The bulk of the caseinase activity also coincided with activity against S2586 (Fig. 2b), a trace being associated with fractions 50-56. It is possible that the organisms produced other enzymes which degraded casein to non-precipitating products; such enzymes would not have been detected.

Recovery of S2586-cleaving activity from DEAE-cellulose chromatography was consistently poorer than that of caseinase activity (Table 1). One reason for this anomaly was found when the pool of fractions with activity against S2586 was added to the preceding ion-exchange fractions, which were then re-assayed with S2586 as substrate (Fig. 3). The cleavage of S2586 was greatly enhanced in the presence of the Leu-AP activities, a synergy further seen in a kinetic study (Fig. 4). However, two- to threefold enhancement of casein precipitation by the Leu-AP enzymes was 


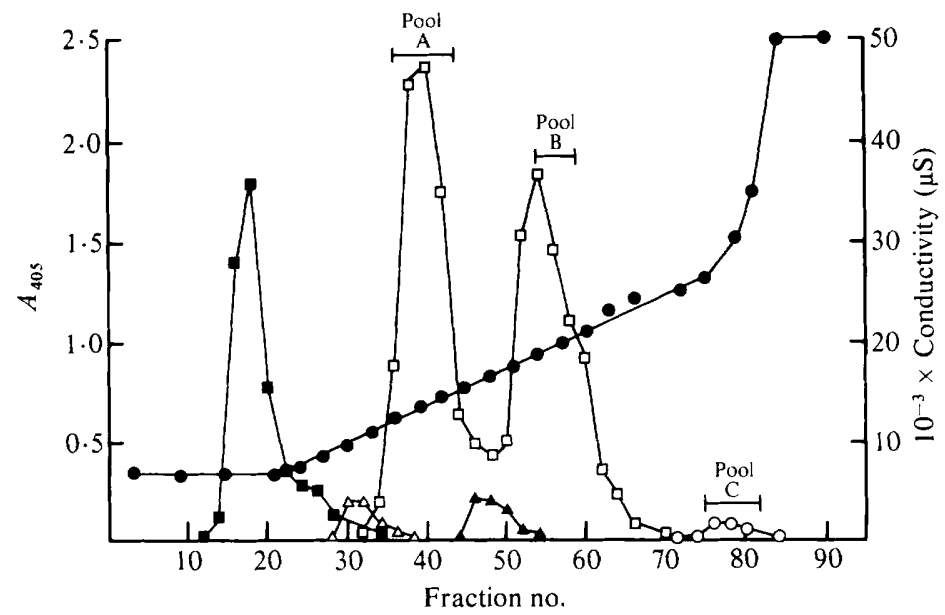

Fig. 1. Separation of $L$. pneumophila proteases by DEAE-cellulose ion-exchange chromatography. Substrates: $\square$, Lys-pNA; $\square$, Leu-pNA; $\triangle$, Ala-pNA; $\boldsymbol{\Delta}, N$-CBZ-Phe-O-NP; O, S2586. Conductivity.
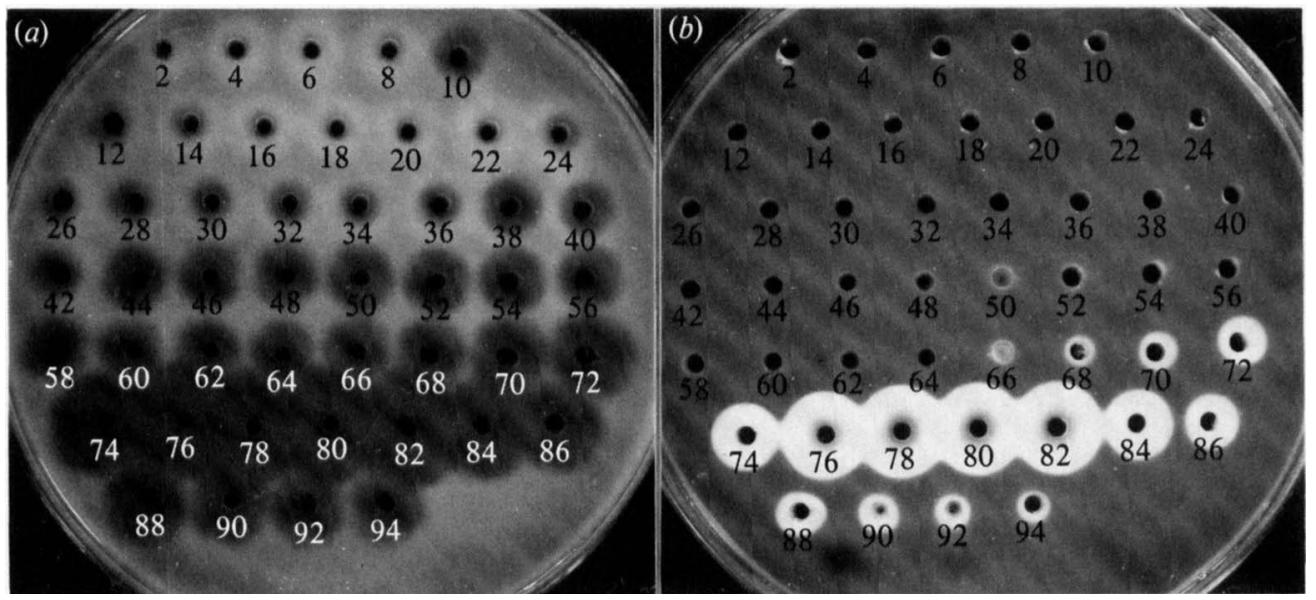

Fig. 2. (a) Gelatin hydrolysis and (b) casein precipitation by ion-exchange fractions (see Fig. 1).

Table 1. Recovery of S2586-cleaving and caseinase activities after DEAE-cellulose ion-exchange chromatography

\begin{tabular}{|c|c|c|c|c|c|}
\hline Substrate & Fraction & $\begin{array}{l}\text { Total activity } \\
\text { (units) }\end{array}$ & $\begin{array}{c}\text { Specific activity } \\
\left.[\text { units (mg protein) })^{-1}\right]\end{array}$ & $\begin{array}{l}\text { Purification } \\
\text { factor }\end{array}$ & $\begin{array}{c}\text { Yield } \\
(\%)\end{array}$ \\
\hline S2586 & $\begin{array}{l}\text { Supernatant broth } \\
\text { Ion-exchange (pool C)* }\end{array}$ & $\begin{array}{c}1495 \\
12.2\end{array}$ & $\begin{array}{r}133 \\
24\end{array}$ & $\begin{array}{r}(1 \cdot 0) \\
0.81\end{array}$ & $\begin{array}{l}100 \\
0 \cdot 18\end{array}$ \\
\hline Casein & $\begin{array}{l}\text { Supernatant broth } \\
\text { Ion-exchange (pool C)* }\end{array}$ & $\begin{array}{r}122880 \\
38400\end{array}$ & $\begin{array}{l}10894 \\
64000\end{array}$ & $\begin{array}{r}(1.0) \\
5.87\end{array}$ & $\begin{array}{l}100 \\
31 \cdot 3\end{array}$ \\
\hline
\end{tabular}

* See Fig. 1. 


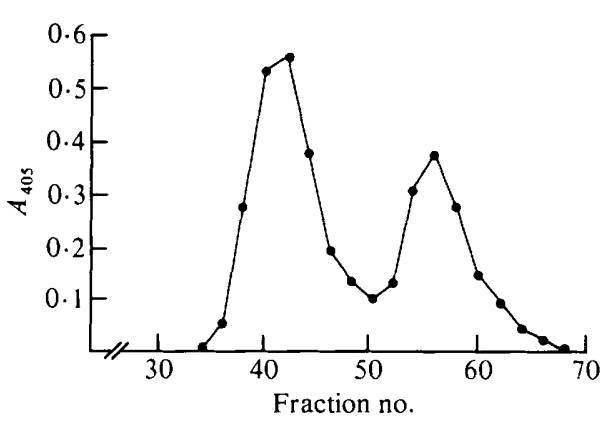

Fig. 3

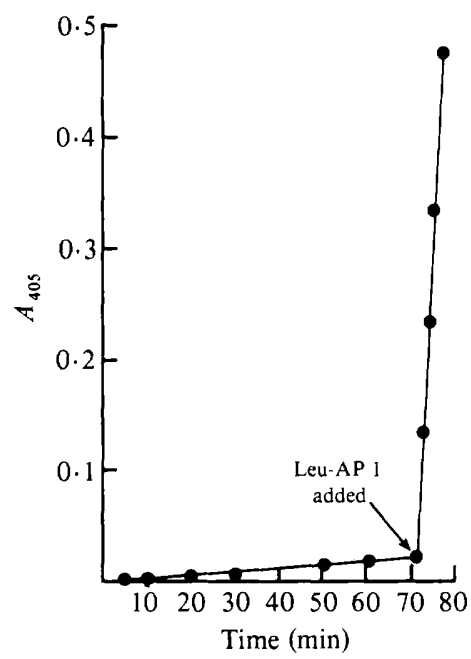

Fig. 4

Fig. 3. Synergistic effect of Leu-APs on cleavage of S2586 by caseinase. Volumes $(50 \mu 1)$ of pooled caseinase from the ion-exchange column (pool C, Fig. 1) were added to $50 \mu \mathrm{l}$ volumes of preceding ionexchange fractions and assayed for S2586-cleaving activity as described in Methods.

Fig. 4. Kinetics of S2586 cleavage in the presence and absence of Leu-AP 1. The rate of cleavage of S2586 by $50 \mu \mathrm{l}$ volumes of caseinase (pool C, Fig. 1) was followed in $1 \mathrm{~cm}$ cuvettes as described in Methods. At $70 \mathrm{~min}, 50 \mu \mathrm{l}$ volumes of Leu-AP 1 (pool A, Fig. 1) were added to all cuvettes, including blanks.

also observed (Fig. 5), so that this synergy provides only a partial explanation for the disparity in recoveries seen in Table 1.

\section{Action of protease on guinea pig skin}

Fig. 6 shows the reaction to intradermal injection of 100 -fold concentrated L. pneumophila culture supernatant and dilutions thereof. Reactions induced by preparations from Corby and Corby avirulent strains were indistinguishable. There was immediate reddening at the site of injection with development of pale central necrosis. The reactions were maximal by $2 \mathrm{~h}$ and the subdermal tissue showed haemorrhage and oedema at post mortem (for pathology see below). Purified L. pneumophila lipopolysaccharide, concentrated fresh broth and heat-treated $(5 \mathrm{~min}$, $100{ }^{\circ} \mathrm{C}$ ) concentrated culture supernatant all failed to elicit any reaction in the skin test.

After ion-exchange chromatography, only fractions with S2586-cleaving/casein-precipitating activity elicited the skin reactions shown in Fig. 6. Pooled, concentrated Leu-AP fractions from either of the Leu-AP peaks gave no detectable increase in skin reaction when injected together with a concentrated pool of S2586-cleaving/casein-precipitating fractions. The latter pool was passed through a Sephadex G-100 column. Activity against casein and S2586 eluted together with tissue-destructive activity over the $M_{\mathrm{r}}$ range 38800-20200. (There was insufficient protein to obtain a $280 \mathrm{~nm}$ profile.) Detectable skin reactions were elicited by doses of the G-100purified S2586-cleaving/casein-precipitating enzyme as low as $2 \mu \mathrm{g}$ (protein). However, SDSPAGE analysis of the pooled active fractions from Sephadex G-100 (Fig. 7, lane 4) showed the presence of two closely spaced bands of apparent $M_{\mathrm{r}} 41000$ and 42000 and a third band of $M_{\mathrm{r}}$ 19800. Comparison with SDS-PAGE of caseinase activity recovered from ion-exchange (Fig. 7, lane 3) showed that no further separation was achieved by passage through Sephadex G-100.

\section{Purification of tissue-destructive protease}

Because of the above findings, Sephadex G-100 gel filtration was used prior to ion-exchange chromatography to allow treatment of larger volumes of culture supernatant (see Methods). 


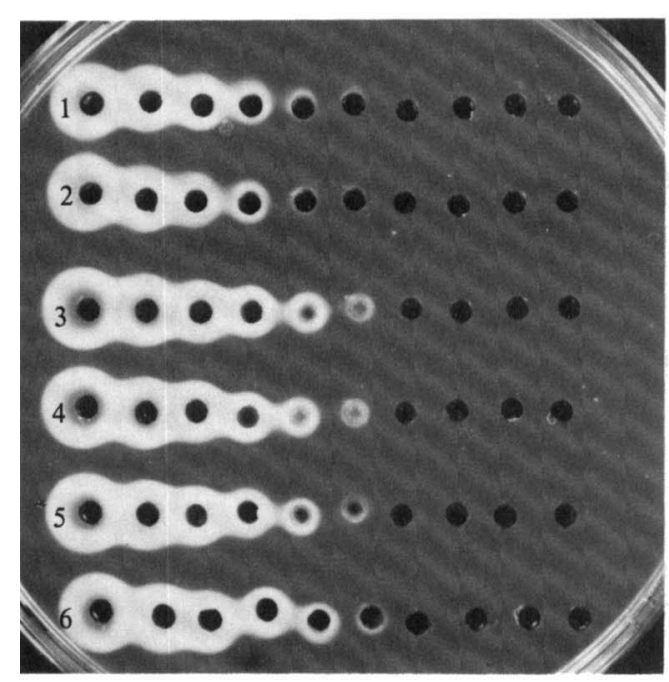

Fig. 5

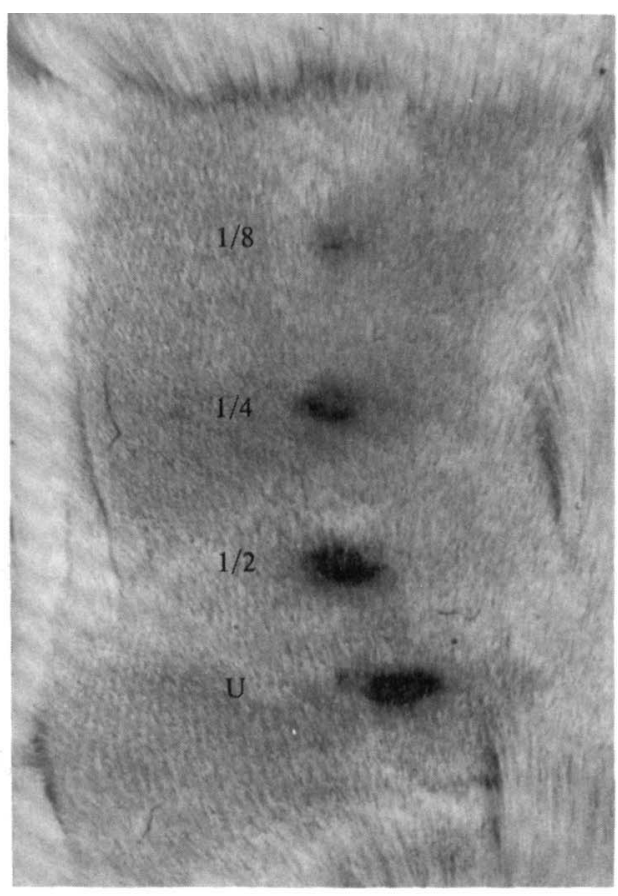

Fig 6

Fig. 5. Enhancement of casein precipitation by Leu-APs. Pooled caseinase (pool C, Fig. 1) was serially diluted with buffer (1 and 2), Leu-AP 1 (pool A, Fig. 1; 3 and 4) or Leu-AP 2 (pool B, Fig. 1; 5 and 6), transferred to casein-agar substrate and incubated at $37^{\circ} \mathrm{C}$ for $16 \mathrm{~h}$.

Fig. 6. Guinea-pig skin test. L. pneumophila culture supernatant concentrated 100 -fold was serially twofold diluted in PBS, $100 \mu \mathrm{l}$ samples were injected intradermally into sites along the shaved flank and results observed after $2 \mathrm{~h}$. $U$, undiluted sample.

When the concentrated pool of ion-exchange fractions containing caseinase activity was then subjected to gel filtration on Sephadex G-50, two peaks of $280 \mathrm{~nm}$ absorbance were obtained (Fig. 8). Maximum activity against S2561 and S2586 substrates was located in the trough between these two peaks, indicating that S2561 and S2586 cleavage required the presence of both protein species. The bulk of the caseinase activity was found in fractions from the first peak of $280 \mathrm{~nm}$ absorbance but activity also extended into the second peak.

SDS-PAGE of fractions from the first and second Sephadex G-50 peaks (indicated in Fig. 8) revealed (Fig. 7, lanes 6 and 7) that the Sephadex G-50 step had separated the two higher $M_{\mathrm{r}}$ species from the lower $M_{\mathrm{r}}$ species. The minor, lower $M_{\mathrm{r}}$ bands present (Fig. 7, lane 6) were probably peptide fragments generated by autolysis, otherwise they would have been in a later fraction from the Sephadex G-50 column. Only the fractions from the first Sephadex G-50 peak were active in guinea-pig skin. This pooled material was designated 'tissue-destructive protease'; it possessed collagenase activity but no elastase activity. The enzyme separation and tissue-destructive protease purification procedures have been performed at least four times, yielding nearly identical elution profiles and activities.

\section{Pathology of skin reactions to protease}

All skin sites injected with control materials or with enzymes other than casein-precipitating protease were histologically normal. Three hours after intradermal inoculation of $8 \mu \mathrm{g}$ of purified tissue-destructive protease, or the equivalent (on the basis of casein precipitation) as unfractionated culture supernatant, there was localized haemorrhage from small blood vessels in the upper dermis which was tracking into the subcutaneous adipose tissue. Polymorphonuclear 


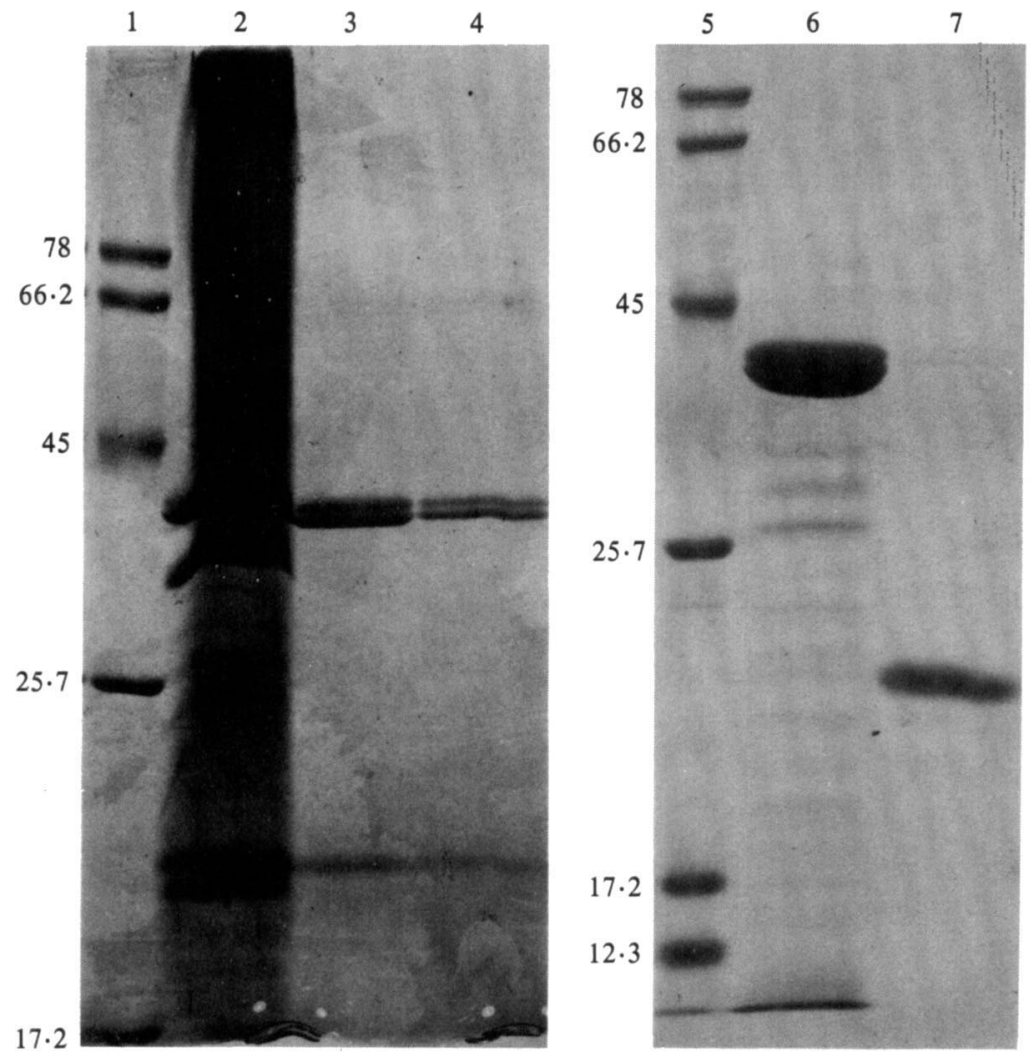

Fig. 7. SDS-PAGE profiles. Lanes 1 and $5, M_{\mathrm{r}}$ markers (values shown $\times 10^{-3}$ ); lane 2, concentrated supernatant broth; lane 3, ion-exchange fractionated caseinase; lane 4, Sephadex G-100 fractionated caseinase: lanes 6 and 7, pools A and B, respectively, from Sephadex G-50 (see Fig. 8).

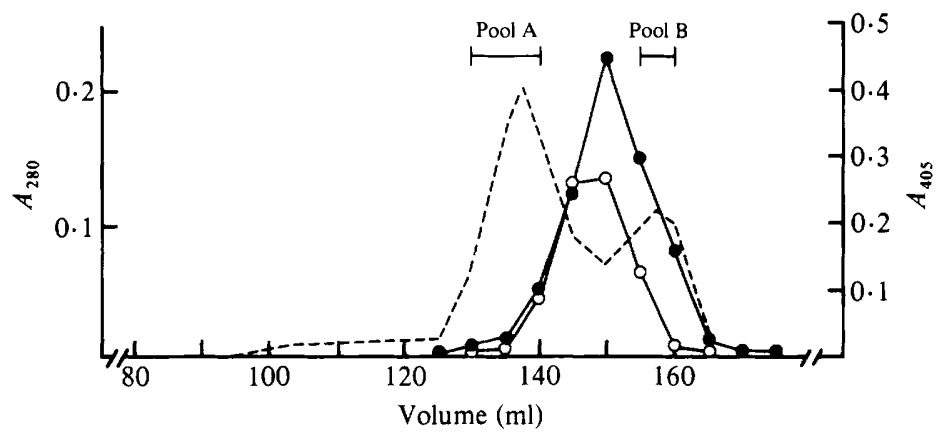

Fig. 8. Elution profile of tissue-destructive protease from Sephadex G-50. Substrates: S2561. -.., $A_{280}$.

leucocyte (PMN) margination was prominent in affected vessels and groups of PMN had emigrated through the walls. In the most severe lesions there was fresh coagulative necrosis of the dermis. Collagen fibres in these areas had apparently disintegrated, leaving an amorphous eosinophilic zone studded with nuclear debris. By $24 \mathrm{~h}$ these lesions had progressed to a severe acute spreading inflammation of the epidermis and dermis. At some sites there were intradermal microabscesses and vesicles, at others total destruction of the epidermis and upper dermis with 
heavy PMN infiltration of hair follicles, dermis, nerves and adipose layer. There was also coagulative necrosis of many fibres in the muscle layer.

\section{Action of tissue-destructive protease in the lung}

Only concentrated culture supernatant or fractions with tissue-destructive activity by the skin test were tested in the lung. All materials, including the purified tissue-destructive protease, were active in the lung, yielding qualitatively similar pathology. Because of the semiquantitative nature of the caseinase assay, precise equivalence of treatment was impossible to achieve. All treated animals showed dyspnoea within $15 \mathrm{~min}$ of the treatment and many of those inoculated intranasally had nasal haemorrhage at this stage. In a number of experiments $9 / 35$ guinea pigs given concentrated culture supernatant by intratracheal or intranasal inoculation died within $30 \mathrm{~min}$ and a further $9 / 35$ died up to $24 \mathrm{~h}$ later. The other 17 animals were killed for histopathology and electron microscopy at 1,2,3 or $4 \mathrm{~d}$. In three experiments a total of 15 guinea pigs were given purified tissue-destructive protease at doses up to $80 \mu \mathrm{g}$ protein. One guinea pig died by $3 \mathrm{~h}$ and the remainder died or were killed for histopathology at times up to $3 \mathrm{~d}$. Postmortem examination up to $3 \mathrm{~h}$ showed changes in the lungs, which had numerous confluent dark red haemorrhagic lesions. Some of these were subpleural, but slices through the lobes showed that the majority were in the central zone. After $24 \mathrm{~h}$ the haemorrhagic consolidation had extended to include much of the lung periphery. Control animals did not show clinical or pathological abnormalities.

\section{Lung histopathology}

In animals killed or dying at $0.5 \mathrm{~h}$ after inoculation the lungs contained numerous foci of intraalveolar haemorrhage and oedema with no cellular response. Affected areas were located principally in the centre of the lobes. Airway epithelium was normal, though a few terminal bronchioles had intraluminal erythrocytes. By $3 \mathrm{~h}$ the areas of alveolar oedema and haemorrhage had increased and contained more fibrin. There were some PMN and occasional macrophages in alveoli, and margination of PMN in pulmonary venules was marked. Airways were normal, though some red cells were present in some small bronchioles. At $24 \mathrm{~h}$ lesions extended to the subpleural regions, forming confluent areas of haemorrhagic pneumonia which involved much of the lobes. Although numerous erythrocytes, oedema and fibrin were present in alveoli, they were often almost obscured by a heavy PMN and macrophage infiltration. Destruction of interalveolar septa had occurred in many areas. By 2-4 d, pulmonary lesions were similar to those at $24 \mathrm{~h}$, except that hyaline membranes were present for the first time in a few areas, forming dense eosinophilic masses lining the walls of respiratory bronchioles and alveoli. The bulk of each lobe was filled by an intense inflammatory exudate of oedema fluid, fibrin, PMN and macrophages, which became progressively more organized.

\section{DISCUSSION}

This study confirms the production by $L$. pneumophila of a number of proteolytic activities previously demonstrated only in crude preparations (Weaver \& Feeley, 1979; Berdal \& Fossum, 1982; Berdal et al., 1982; Müller, 1981). Using anion-exchange and gel filtration techniques efficient separation of some of these activities has been achieved. Of particular interest was the one proteolytic activity which caused damage to the skin of guinea pigs. This enzyme was chosen for purification and study in the lung as a potential cause of the tissue damage in Legionnaires' disease. A role for Legionella proteases and toxins has previously been postulated (Thorpe \& Miller, 1981; Baine, 1985) but the histopathology of the pulmonary damage caused by the purified enzyme in this study provides the first evidence that a Legionella protease can produce lesions which are closely similar to those of experimental Legionnaires' disease (Baskerville et al., 1981, 1986).

The tissue-destructive protease eluted from Sephadex G-100 with an apparent $M_{\mathrm{r}}$ of 38000 and ran as two closely spaced bands $\left(M_{\mathrm{r}} 41000\right.$ and 42000$)$ on SDS-PAGE. The elution profile from Sephadex G-100 makes it unlikely that these two bands are subunits of a larger native 
enzyme. Although the possibility of one of these bands being a contaminant cannot be ruled out, they may represent active and inactive forms of the enzyme, or alternatively two isoenzymes may be present. The possibility that the minor bands (Fig. 7, lane 6) result from autolysis is supported by the finding of Berdal \& Fossum (1982) that casein-precipitating activity disappears from cultures of $L$. pneumophila with prolonged incubation. In addition to precipitating casein this enzyme, in conjunction with others, cleaves the Kabi substrates S2561 and S2586. This complex synergy renders such substrates unsuitable for kinetic studies, especially when assaying crude material.

Berdal \& Fossum (1982) demonstrated the production of casein-precipitating activity by $L$. pneumophila, L. bozemanii, $L$. gormanii and $L$. dumoffii, but not by $L$. micdadei. In addition $L$. micdadei cleaves S2586 only weakly and S2561 not at all (Berdal et al., 1982). Possibly the strain used was a non-producer or $L$. micdadei produces a tissue-destructive enzyme different from those of other species (one which lacks specificity for casein and chromogenic substrates), or only produces this activity in vivo. In support of this latter possibility Müller (1983) has demonstrated the induction of proteases in L. pneumophila by serum proteins. L. micdadei appears to cause pneumonia only in immunocompromised persons and thus may not need to produce this enzyme in such high quantities as do other species.

Inhibition of casein-precipitating enzyme by normal serum has been demonstrated by both Berdal \& Fossum (1982) and ourselves (data not included). Therefore natural antiprotease in the lung might be important in neutralizing protease activity during infection with legionellae. Abrams et al. (1984) have demonstrated reduced levels of antiprotease activity in the lungs of patients, mainly elderly and with underlying disease, suffering from a variety of bacterial pneumonias. In addition Pryor et al. (1984) have demonstrated inactivation of antiprotease by cigarette smoke. Age, underlying illness and smoking are three of the main risk factors for the acquisition of Legionnaires' disease.

We are currently investigating the in vivo production of this enzyme in guinea pigs with pulmonary Legionnaires' disease and the potential of anti-protease antibody for protection. The roles of the other proteases produced by $L$. pneumophila are also being examined.

This work was funded by an MRC project grant. We thank KabiVitrum for the gift of S2561.

\section{REFERENCES}

Abrams, W. R., Fein, A. M., Kucich, U., KuepPers, F., Yamada, H., Kuzmowycz, T., Morgan, L., Lippmann, M., Goldberg, S. K. \& Weinbaum, G. (1984). Proteinase inhibitory function in inflammatory lung disease. American Review of Respiratory Diseases 129, 735-741.

BAINE, W. B. (1985). Cytolytic and phospholipase C activity in Legionella species. Journal of General Microbiology 131, 1383-1391.

Baskerville, A., Fitzgeorge, R. B., Broster, M., Hambleton, P. \& Dennis, P. J. (1981). Experimental transmission of Legionnaires' disease by exposure to aerosols of Legionella pneumophila. Lancet ii, 1389-1390.

Baskerville, A., Fitzgeorge, R. B., Broster, M. \& Hambleton, P. (1983). Histopathology of experimental Legionnaires' disease in guinea-pigs, rhesus monkeys and marmosets. Journal of Pathology 139, 349-362.

Baskerville, A., Conlan, J. W., Ashworth, L. A. E. \& DowseTt, A. B. (1986). Pulmonary damage caused by a protease from Legionella pneumophila. British Journal of Experimental Pathology (in the Press).

Berdal, B. P. \& Fossum, K. (1982). Occurrence and immunogenicity of proteinases from Legionella species. European Journal of Clinical Microbiology 1, 7-11.

Berdal, B. P., Olsvik, O., Myhre, S. \& Omland, T. (1982). Demonstration of extracellular chymotrypsin-like activity from various Legionella species. Journal of Clinical Microbiology 16, 452-457.

Blackmon, J. A., Chandler, F. W., Cherry, W. B., England, A. C., Feeley, J. C., Hicklin, M. D., MCKinNey, R. M. \& Wilkinson, H. W. (1981). Legionellosis. American Journal of Pathology 103, $429-465$.

BRADFORD, M. (1976). A rapid and sensitive method for the quantitation of microgram quantities of protein utilising the principle of protein-dye binding. Analytical Biochemistry 72, 248-254.

Conlan, J. W. \& Ashworth, L. A. E. (1986). The relationship between the serogroup antigen and lipopolysaccharide of Legionella pneumophila. Journal of Hygiene 96, 39-48.

CUlling, C. F. A. (1963). Handbook of Histopathological Techniques, 2nd edn. London: Butterworths.

EDElsteIn, P. H. (1981). Improved semiselective medium for isolation of Legionella pneumophila from contaminated clinical and environmental specimens. Journal of Clinical Microbiology 14, 298-303.

Gray, L. \& Kreger, A. (1979). Microscopic charac- 
terisation of rabbit lung damage produced by Pseudomonas aeruginosa proteases. Infection and Immunity 23, 150-159.

homma, J, Y., Abe, C., Tanamoto, K., Hirao, Y., Morihara, K., Tsuzuki, H., YanaGawa, R., Honda, E., AOI, Y., FUJimoto, Y., Goryo, M., IMAZEKI, N., NODA, H., Goda, A., TAKeUChI, S. \& IsHIHARA, T. (1978). Effectiveness of immunisation with single and multi-component vaccines prepared from a common antigen (OEP), protease and elastase toxoids of Pseudomonas aeruginosa on protection against hemorrhagic pneumonia in mink due to $P$. aeruginosa. Japanese Journal of Experimental Medicine 48, 111-133.

Jepras, R. I., Fitzgeorge, R. B. \& Baskerville, A. (1985). A comparison of virulence of two strains of Legionella pneumophila based on experimental aerosol infection of guinea-pigs. Journal of Hygiene 95, 29-38.

Kortt, A. A., Burns, J. E. \& Stewart, D. J. (1983). Detection of the extracellular proteases of Bacteroides nodosus in polyacrylamide gels: a rapid method of distinguishing virulent and benign ovine isolates. Research in Veterinary Science 35, 171-174.

LAEMMLI, U. K. (1970). Cleavage of structural proteins during the assembly of the head of bacteriophage T4. Nature, London 227, 680-684.

LYERLY, D. M. \& KREGER, A. S. (1983). Importance of Serratia protease in the pathogenesis of experimental Serratia marcescens pneumonia. Infection and Immunity 40, 113-119.

Medical Research Council (1974). The Accreditation and Recognition Schemes for Supplies of Laboratory Animals. MRC Laboratory Animals Centre Manual Series 1. Carshalton, Surrey: Medical Research Council.
MÜLLER, H. E. (1980). Proteolytic action of Legionella pneumophila on human serum proteins. Infection and Immunity 27, 51-53.

MÜLLER, H. E. (1981). Enzymatic profile of Legionella pneumophila. Journal of Clinical Microbiology 13, 423-426.

MüllER, H. E. (1983). Induction of proteinases in Legionella by growth on agar containing serum. Zentralblatt für Bakteriologie, Mikrobiologie und Hygiene 256, 211-221.

Pryor, W. A., Dooley, M. M. \& Church, D. F. (1984). Inactivation of human $\alpha$-1-proteinase inhibitor by gas-phase cigarette smoke. Biochemical and Biophysical Research Communications 122, 676-681.

Ristroph, J. D., Hedlund, K. W. \& Allen, R. G. (1980). Liquid medium for growth of Legionella pneumophila. Journal of Clinical Microbiology 11, 1921.

ThOMPSON, R., MilleR, R. D. \& IGlewsKi, B. H. (1981). In vitro production of an extracellular protease by Legionella pneumophila. Infection and Immunity 34, 299-302.

ThORPE, T. C. \& Miller, R. D. (1981). Extracellular enzymes of Legionella pneumophila. Infection and Immunity 33, 632-635.

Weaver, R. E. \& Feeley, J. C. (1979). Cultural and biochemical characterisations of the Legionnaires' disease bacterium. In 'Legionnaires': the Disease, the Bacterium and Methodology, pp. 19-26. Edited by G. L. Jones \& G. A. Herbert. Atlanta, Georgia: Center for Disease Control.

Woods, D. E., Cryz, S. J., Friedman, L. \& IGLewski, B. H. (1982). Contribution of toxin A and elastase to virulence of Pseudomonas aeruginosa in chronic lung infection of rats. Infection and Immunity 36, 12231228. 